\title{
RETRACTED ARTICLE: Evaluating groundwater level fluctuation by support vector regression and neuro-fuzzy methods: a comparative study
}

\section{Mohammad Mirzavand ${ }^{1} \cdot$ Benyamin Khoshnevisan ${ }^{2} \cdot$ Shahaboddin Shamshirband $^{3}$. Ozgur Kisi ${ }^{4} \cdot$ Rodina Ahmad $^{5}$. Shatirah Akib ${ }^{6}$}

Received: 4 October 2014 / Accepted: 3 January 2015 / Published online: 22 January 2015

(c) Springer Science+Business Media Dordrecht 2015

The Editor-in-Chief has retracted this article [1] because the validity of the content of this article cannot be verified. This article showed evidence of substantial text overlap (most notably with the articles cited [2-6]), peer review and authorship manipulation. Mohammad Mirzavand has not explicitly stated whether he agrees to this retraction notice. None of the other co-authors responded to correspondence about this retraction.

\section{References}

1. Akib S, Rahman S, Shamshirband S, Petković D (2015) Soft computing methodologies for estimation of bridge girder forces with perforations under tsunami waveloading. BullEarthq Eng 13(3):935-995

Electronic supplementary material The online version of this article (https://doi.org/10.1007/s1106 9-015-1602-4) contains the full text of the retracted article as electronic supplementary material.

Shahaboddin Shamshirband

shamshirband@um.edu.my

1 Department of Watershed Management, Faculty of Natural Resources and Earth Sciences, University of Kashan, Kashan, Iran

2 Department of Agricultural Machinery Engineering, Faculty of Agricultural, Engineering and Technology, University of Tehran, Karaj, Iran

3 Department of Computer Systems and Information Technology, Faculty of Computer Science and Information Technology, University of Malaya (UM), 50603 Kuala Lumpur, Malaysia

4 Department of Civil Engineering, Faculty of Architecture and Engineering, Canik Basari University, 55080 Samsun, Turkey

5 Department of Software Engineering, Faculty of Computer Science and Information Technology, University of Malaya (UM), 50603 Kuala Lumpur, Malaysia

6 Department of Civil Engineering, Faculty of Engineering, University of Malaya (UM), 50603 Kuala Lumpur, Malaysia 
2. Mirzavand M, Ghazavi R (2015) A Stochastic Modelling Technique for Groundwater Level Forecasting in an Arid Environment Using TimeSeries Methods. Water Resour Manage 29(4):1315-1328

3. Mirzavand M, Khoshnevisan B, Shamshirband S, Kisi O, Ahmad R, Akib S (2015) Evaluating groundwater level fluctuation by support vector regression and neuro-fuzzy methods: acomparative study. Nat Hazards 2015:1-15

4. Ramedani Z, Omid M, Keyhani A, Shamshirband S, Khoshnevis B (2014) Potential of radial basis function based support vector regression for global solar radiation prediction. Renew Sustain Energy Rev 39:1005-1011

5. Zakaria R, Noh SMC, Petković D, Shamshirband S, Penny R (2014) RETRACTED: Investigation of plasmonic studies on morphology of deposited silver thin films havingdifferent thicknesses by soft computing methodologies-A comparative study. Phys E: LowdimensionalSyst Nanostruct 63:317-323

6. Zakaria R, Sheng OY, Wern K, Shamshirband S, Wahab AWA, Petković D, Saboohi H (2014) Examination of tapered plastic multimode fiber-based sensor performance with silver coating for different concentrations of calcium hypochlorite by soft computing methodologies - a comparative study. J Opt Soc Am A 31(5):1023-1030 